\title{
Educating Nonlinearly and Visually in the Digital Knowledge Age: A Delphi Study
}

\author{
Ammar H. Safar ${ }^{1}$ \\ ${ }^{1}$ College of Education, Kuwait University, The State of Kuwait \\ Correspondence: Ammar H. Safar, College of Education, Kuwait University, P.O. Box 13281, Kaifan, 71953, \\ The State of Kuwait. Tel: 965-2463-2461. E-mail: dr.ammar@ku.edu.kw
}

Received: September 20, 2015 Accepted: February 18, 2016 Online Published: March 18, 2016

doi:10.5539/ass.v12n4p11

URL: http://dx.doi.org/10.5539/ass.v12n4p11

\begin{abstract}
This longitudinal, qualitative and Delphi technique-designed research study sought a reasonable consensus for identifying and prioritizing the best and most appropriate Web 2.0/3.0 nonlinear visual tools that can revolutionize the educational processes of thinking, teaching, learning, and leading in the digital knowledge age. The study also sought reasonable agreement on the criteria to measure the educational success of these new breeds of information and communication technology (ICT) tools. The results were very promising. The Delphi ICT experts, 80 personnel in total, reached significant agreement on the issues that were carefully deliberated in this study. The Delphi participants prioritized a list of the most relevant, reliable, and appropriate Web 2.0/3.0 nonlinear visual tools that can enhance the educational processes of thinking, teaching, learning, and leading in the digital knowledge age. Additionally, the participants recognized and prioritized certain criteria (i.e., measurements, standards, factors, benchmarks, and principles) that can assess and measure the success of Web 2.0/3.0 nonlinear visual tools and any ICT platform from educational perspectives. No significant differences were found among the Delphi subgroups when inferential statistics were performed. The qualitative nature of the Delphi technique research design, the deployment period, and the capability of examining a large sample size of ICT experts all notably helped in strengthening the statistical significance, reliability, and confidence in the collected data. The findings of this study comply with the postulated assumptions. These results can assist academics, educators, instructional technology leaders, practitioners, administrators, and policy and decision makers in ascertaining and defining appropriate solutions to educational challenges.
\end{abstract}

Keywords: assessment, Delphi technique, education, ICT tools, measurement, nonlinear visual tools, Web 2.0 tools, Web 3.0 tools

\section{Introduction}

Most of the research studies that have been conducted in the past 10-15 years have ascertained that more than 70 percent of the information that goes nonlinearly into the brain is visual. Nonlinear visual thinking does not demand any artistic skills but instead occurs naturally in your brain. Your ability to draw a wonderful sketch does not relate to how well you can think visually. Researchers contend that approximately 60 percent of people are visual thinkers whose favored mode of thinking, teaching, and learning is to visualize. This finding does not mean that these people are practicing artists (Diamond, 2010). Information and communication technology (ICT) significantly promotes the creation, collaboration, and diffusion of knowledge nonlinearly and visually (United Nations Educational, Scientific and Cultural Organization [UNESCO], 2005; United Nations Educational, Scientific and Cultural Organization [UNESCO], 2013). ICT can help open new opportunities to stimulate nonlinear visual education -i.e., nonlinear and visual thinking, teaching, and learning. Accordingly, from a global perspective, educators and scholars always encourage ICT to advance excellence in education and to bring academic institutions into the digital knowledge age, which emphasizes visual aids, or visuals, as alternatives that support 21st century knowledge, skills, and competencies. These skills include storytelling, storyboarding, mind mapping, critical thinking, visual thinking, analytical thinking, multidimensional nonlinear thinking, nonlinear visual teaching and learning, nonlinear visual leadership, problem solving, decision making, debating, persuading, communicating, collaborating, sharing, creating, and innovating.

\section{Objectives of the Study}

The study's main objective is to identify a prioritized list of appropriate ICT tools/services that can be used as 
nonlinear visual aids and that can enhance the educational process of thinking, teaching, learning, and leading in the digital knowledge age. This study also attempted to recognize the attributes for measuring the educational success of ICT tools/services. Accordingly, the following questions are addressed in this study.

1. What are the most appropriate Web 2.0/3.0 tools that embrace nonlinear visual thinking, teaching, and learning?

2. What should be the criteria for measuring the educational success of Web 2.0/3.0 tools that support nonlinear visual thinking, teaching, and learning?

3. Are the criteria for measuring the educational success of Web 2.0/3.0 tools that embrace nonlinear visual thinking, teaching, and learning different from other educational application software?

\section{Assumptions and Limitations of the Study}

This study assumes that an agreement would easily emerge among ICT experts regarding the research questions that are under investigation. These experts would simply recognize the nonlinear visual tools that can enhance educational processes in the digital knowledge age. These experts would also effortlessly identify the criteria for measuring the educational success of such applications.

This research was directed only at ICT experts. The perceptions and judgments of only 80 ICT experts were used for data analysis purposes. The inability to scrutinize a large sample size is because of the qualitative nature of the research design. Namely, the Delphi technique model that is used is time-consuming. As a result, the study's findings are limited by the number of experts and the number of institutions that they represent. Additionally, the rapidity of the decision making process is somewhat controlled by the participants (Anantatmula, 2007; Hsu \& Sandford, 2007; Skulmoski, Hartman, \& Krahn, 2007).

\section{Significance of the Study}

Visuals have played a significant role in education for some time and have changed dramatically over time. However, most of the visual aids that are used in Kuwait's educational institutions - and the Cooperation Council for the Arab States of the Gulf, hereinafter referred to as the Gulf Cooperation Council (GCC), as well as the Middle East region - are considered somewhat old fashioned from the ICT perspective. The new breeds of ICT that were developed during the past decade - mainly after the emergence of Web 2.0 tools and services at the end of 2003 - have opened new horizons and opportunities for visuals in the educational processes of thinking, teaching, learning, and leading. The potential of these new visual aids is limitless. Introducing these new visual tools and services is inevitable because of the significant advances in ICT; modern visual tools are also necessary because individuals are bored with and bombarded by old technologies. The acceptance of any new technology is predominantly influenced by its perceived effectiveness and usefulness and is implicitly influenced by its job relevance and perceived ease of use (Thielsch \& Perabo, 2012). Therefore, this research study was conducted to identify a prioritized list of Web 2.0/3.0 tools that may be introduced to the college of education (COE) pre-service teachers at Kuwait University (KU) as new types of nonlinear visuals that can enhance the educational processes of thinking, teaching, learning, and leading. The study was also conducted to prudently recognize certain criteria for measuring the educational success of any ICT tool. These identified assessment measurements or attributes, if applied properly, can assist academics and practitioners to visibly evaluate the impacts of these new nonlinear visuals on thinking, teaching, learning, and educational leadership. Performing these types of studies will increase the awareness, impacts, and acceptance of these new nonlinear visual tools in academic institutions and is considered to be extremely vital and worthwhile. This study's results may assist scholars, academics, educators, teachers, administrators, instructional technology leaders, professionals, practitioners, and policy and decision makers in determining and defining appropriate solutions to educational challenges.

\section{Literature Review}

\subsection{What Is Neuroscience?}

Neuroscience is the study of the brain. The workings of the brain have been the focus of scientific and academic research and popular literature for hundreds of years. However, scientists believe that 90 percent of the accumulated knowledge concerning the brain was discovered and learned in the last 14 years of the 21 st century because of the significant advances in ICT. For this reason, as scientists became more sophisticated in the way that they read the brain with scanners, they increasingly discovered astounding new facts including how people process information, evoke and factor in emotions, and boost memorization-i.e., how people see, think, understand, learn, and communicate. One of the main findings that astonished scientists and scholars is the fact that the brain has the capability to develop and transform no matter its age. The brain is not fixed and 
unchangeable. This phenomenon is known as "plasticity", which means that people can develop new mindsets when they want. Other new facts that have been discovered concerning the brain can help you make presentations prominent and more fun, effective, compelling, understandable, and memorable. Some of these strategies involve ways of presenting ideas visually, in small amounts, in a specific order, and at certain intervals (Arden, 2010; Diamond, 2010).

Several research-proven techniques have become popular in recent years that educators can utilize to effectively and efficiently communicate visually. (1) Distilling the information (i.e., messages) to its most basic form-by using keywords and phrases - in fun, interesting, and visual ways enables the audience to see the information and respond to it emotionally. Thus, presenting less information visually makes it more relevant, understandable, and memorable by emphasizing and communicating importance. This idea is fortified by burgeoning concepts such as "Information Triage". Accordingly, thinking, teaching, and learning require that people always refine each idea to its core components because this is how the brain naturally works (Sheffield Marketing Partners, 2013; Simon, 2011). (2) Another technique is appropriately ordering the presented information based on its primacy, recency, and relatedness. (3) In addition, the utilization of John Medina's 10-minute transitions/intervals rule recommends a shift in presentation mode approximately every 10 minutes to constantly grab people's attention (Medina, 2014). (4) Constructing experiences that are memorable and commendable is another popular method. (5) Moreover, colors can be applied to accentuate ideas, incite creativity, and extend understanding. Recent studies have shown that colors affect people's thinking, and the brain's cortex (i.e., the thinking part) is stimulated by the sight of various colors in different forms. For example, research studies have indicated that people are likely to be more creative when they use the color blue in their creative tasks, and the use of at least three different colors in a presentation is recommended to stimulate the brain's cortex. (6) Another technique is to create spatial relations by using and manipulating space, dimension, movement, contrast, and time along a continuum in a truly unique way. (7) Creating patterns - small design features that are continuously repeated, which form a larger design, i.e., the big picture - enables envisioning the larger picture of something, which makes it much easier to comprehend. (8) Additionally, the brain's ability to process visuals is astonishingly strong and more effective - it is the largest system in the brain. Therefore, using visuals helps to draw viewers into the action and engages both their innovative and creative sides. (9) Using dynamic movement to demonstrate information also adds momentum to a presentation and helps to make it more relevant, memorable, and easier to understand. (10) Adding Web links that can be accessed in a presentation can create the sense of a more dimensional presentation. (11) Another method is collaborating and sharing a presentation with other people virtually. (12) Finally, special multimedia comments - i.e., audio and video comments - can be developed and embedded in a presentation to be played either at the start or the end of the presentation, especially when sharing the presentation without a presenter (Diamond, 2010).

\subsection{Understanding Nonlinear Visual Thinking}

Most conventional software applications, including presentations apps, were initially developed to adhere to a hierarchical systematic structure-which does not align with how people think. These traditional applications reflect linear visual thinking, which requires that people follow a step-by-step development of ideas from point "A" to point "B". Linear visual thinking forces individuals to progress from one concept to another without relation to or integration with the foundational concept (Diamond, 2010; Rockinson-Szapkiw, Knight, \& Tucker, 2011). Linear visual thinking has been highly advocated in the business arena for some time because it emphasizes the logical and analytical. However, the increasing ubiquity of these applications in education raises complex questions involving thinking, pedagogy, learning, education leadership, and the creation of dynamic and effective teaching and learning environments (Hill, Arford, Lubitow, \& Smollin, 2012).

Although linear visual thinking may be a suitable method to organize collected data, nevertheless, it does not reflect how individuals think, understand, memorize, and learn. Therefore, there has been increasing recognition of the value and usefulness of nonlinear visual thinking-which inspires knowledge creation through higher-order thinking skills in a manner that exploits visual, textual, auditory, kinesthetic, and social channels (Rockinson-Szapkiw et al., 2011). The demand for more knowledge workers (i.e., digital citizens) in the 21st century emphasizes the essential need for individuals who can perform both linear and nonlinear visual thinking equally well — because both ways are equally powerful (Watrall, 2009).

Nonlinear visual thinking signifies free connection. Your brain fortifies your aptitude to combine concepts, and your brain can create limitless numbers of associations. Ideas may flow in all directions, and a hierarchy cannot present itself until a significant amount of information is revealed. Your mind creates associations and connections as they come to you (Arden, 2014; Diamond, 2010). Nonlinear visual thinking is the manner in which your brain functions. As a result, and precisely because of the emergence of Web 2.0 tools and services in 
late 2003, new applications are being developed as a solution to the rigid, linear visual structure that is embedded in traditional programs. Thus, these new nonlinear visual thinking software applications are a more natural way to cultivate creativity and innovation. These applications do not require you to create a hierarchy and fill in things in sequence, which an outline or a flowchart requires. These applications impart a totally different type of experience for you as the presenter. With these new tools, you do not move in a traditional linear fashion from point to point or from slide to slide. Instead, you have the freedom and capability to move in any order that makes sense to you to make your case. No idea is accumulating in a row waiting its turn to be presented and seen. With these new apps, you unleash your aptitude to create associations and connections at lightning speed. This capability allows you to utilize comparisons when appropriate and to answer questions more fully (Diamond, 2010; Perron \& Stearns, 2011); thus, you can perceive, understand, memorize, and learn more information more effectively.

\subsection{Nonlinear Visual Thinking in the Classroom}

Contemporary learners are confronted with economic challenges that preceding generations have not experienced. Therefore, scholars and educators must provide methods to assist learners to become more successful. With significant advances in ICT, neuroscience, and psychology, currently, educators can teach and students can learn by utilizing proven successful methods and strategies - which embrace nonlinear visual thinking - that will assist them in attaining their objectives (Arden, 2014; Diamond, 2010).

The majority of individuals did not grow up eager to think nonlinearly and visually. Nonlinear visual thinking was certainly not conferred in classrooms unless you studied to become a professional artist. In the past several years, two reasons have allowed the concept of nonlinear visual thinking to come into its own. (1) First, advances in ICT have guided the availability of numerous tools that help individuals to more easily express themselves nonlinearly and visually. (2) Second, advances in neuroscience have led scientists to successfully discover new means to investigate what occurs when the human brain encounters information (Arden, 2014; Diamond, 2010).

Although it may sound counterintuitive given that it is primarily only a process, nonlinear visual thinking is actually extremely imperative in our everyday lives because of its unique ability to see with both the eyes and the mind's eyes. You can see something with your mind's eyes and then sketch a depiction of it without using any special tools beyond a pencil (Diamond, 2010).

Educators should not doubt why visuals work in the classroom. Numerous recent research studies have clearly indicated that students' knowledge, skills, and competencies improved considerably when visuals were included in the study materials. Examples of these improvements include test scores, final grades, reading ability, writing proficiency, visual thinking capability, critical thinking ability, analytical thinking proficiency, and problem solving capability. Because more than 70 percent of the sensory stimuli that individuals absorb is visual, these improvements are not astonishing (Diamond, 2010).

\subsection{Evidence of Effectiveness}

During the past 10 years, numerous academic and scientific research studies have shown that using nonlinear visual thinking techniques and tools in education - to facilitate teaching, learning, and leading (i.e., education leadership) - have great implications. These studies have significantly documented the abilities of these new nonlinear visual apps in providing various benefits, for teachers and learners alike, when they were used in education to enable tools for thinking, teaching, learning, and leading.

The following are some examples of these impacts. (1) Nonlinear visual apps allow receiving multiple forms and amounts of information nonlinearly and visually in an attractive and interactive manner. This ability means moving away from the industrialized classroom culture that has dominated educational settings for centuries. This ability enriches the process of understanding and integrating new knowledge; thus, nonlinear visual apps support the nature of knowledge learning and acquisition (Diamond, 2010; Zhang, 2012). (2) Nonlinear visual apps enable different teaching methods and learning strategies in ways that were not previously available, and they promote different learning styles (Girvan, 2010; Jensen \& Tunon, 2012). (3) Nonlinear visual apps capture individuals' attention and, as a result, enable them to be more motivated and highly engaged in their own teaching and learning activities (e.g., projects, assignments, tasks, readings, etc.) (Jacobson, 2012-13; Yanchus, 2013). (4) Nonlinear visual apps also enhance learner-centered interaction and cooperation (i.e., they help develop social and emotional learning skills) in classroom instruction more quickly and effectively through their real-time team collaboration and sharing functionalities (Schiller, 2011; Virtanen, Myllärniemi, \& Wallander, 2013). Nonlinear visual apps help individuals to collaborate, cooperate, and share with others more effectively and efficiently — which can enrich right-brain and left-brain individuals' aptitudes to understand one another 
equally, more effectively, and more quickly by utilizing a common language; in addition, each person can understand his/her role in relationship to the group (Diamond, 2010). (5) Nonlinear visual apps empower learners' perceptions and understanding (i.e., what they learn), and they enable people to learn faster and to understand and remember more (Diamond, 2010; Jensen \& Tunon, 2012). (6) Nonlinear visual apps assist individuals in observing patterns and making better connections and in understanding interrelations among essential ideas and items in a systematic multi-dimensional fashion; visual processing is conducted by envisioning the parts as a cohesive whole (Diamond, 2010; Virtanen et al., 2013). (7) Finally, nonlinear visual apps stimulate the brainstorming, gathering, organizing, classifying, analyzing, clarifying, simplifying, saving, retrieving, presenting, and sharing of ideas, concepts, information, and all types of data more appealingly and effectively in a structured-manner-i.e., in small pieces (Panag, 2010). Nonlinear visual apps succeed in imparting to learners the knowledge that is required in class more interestingly and efficiently (Diamond, 2010).

Other examples of the educational benefits of these new nonlinear visual tools may include the following. (1) They help to decrease procrastination and enhance productivity. (2) These tools enable people to solve problems and make decisions. (3) Nonlinear visual tools allow people to access their right and left brains simultaneously, which yields a more creative and innovative output. (4) These tools help individuals to think and work in a nonlinear visual fashion, which is the same way that their brains work. (5) Nonlinear visual tools also assist people in becoming more empathetic. (6) These tools impact people's ability to understand, map, and navigate their environments so that each person can interact with his/her own environment. (7) They have the ability to reveal highly integrated knowledge frameworks that are vital for facilitating cognitive activities, which help to maintain and improve students' cognitive skills (Diamond, 2010). (8) Nonlinear visual tools empower a new mindset for their users because they enable the expanding of innovative and unique possibilities that sit somewhere between whiteboards and conventional visuals, which allows a nonlinear, free-flowing presentation of a storyline alongside a linear storyline by using a storyboard approach (Perron \& Stearns, 2011; Virtanen et al., 2013). Finally, (8) these tools facilitate many other uses beyond nonlinear visual teaching and learning presentations, such as storytelling, mind mapping concepts in multiple dimensions, note-taking, constructing timelines, exhibiting work plans, demonstrating individuals' hobbies, sharing information such as photos and recipes, showing individuals' scrapbooks, and displaying special events (Diamond, 2010).

\section{Methodology}

\subsection{Research Design}

The Delphi technique research design was utilized to achieve the objectives of this qualitative study. This model uses a group of experts (i.e., individuals who have a deep understanding of the issues) to carefully and anonymously deliberate a research topic, phenomenon or dilemma when there is insufficient knowledge regarding the subject. This design methodology is characterized by the following four key features: (1) anonymity of the participants, which means that the Delphi participants do not know and do not interact with one another; (2) iteration, which means that the participants can refine their opinions and judgments in every round based on the progress of the group's work; (3) controlled feedback, which means that the Delphi participants are constantly informed concerning the other participants' viewpoints, and provides them the opportunity to elucidate or alter their perspectives; and (4) statistical aggregation of group response, which means that a quantitative analysis and interpretation of data can be conducted (Anantatmula, 2007; Keeney, Hasson, \& McKenna, 2011; Skulmoski et al., 2007). Therefore, this methodology bypasses the disadvantages of conventional groups.

This technique was initially developed by the RAND Corporation in the 1950s and was later improved by the U.S. government. The scope of its uses ranges from forecasting and identifying to making group decisions, developing concepts/frameworks, scrutinizing the strengths and weaknesses of the existing ICT tools/services, generating lists of objectives and indicators of successful programs, examining the effectiveness of newly implemented applications, and discerning the attribute dimensions for characterization purposes (Anantatmula, 2007; Okoli \& Pawlowski, 2004; Skulmoski et al., 2007).

The decision behind utilizing this research design was based on the results that were found in the literature review, which significantly affirmed that the individuals who are knowledgeable in ICT can better address the topic under investigation. The Delphi approach is a global research methodology that is used by researchers and practitioners in various research arenas. The Delphi method is a well-established and very flexible research model (Anantatmula, 2007; Keeney et al., 2011; Skulmoski et al., 2007).

In addition, the Delphi technique was supplemented with several survey questionnaires to expedite the decision making process. Additionally, in-depth interviews and personal discussions were occasionally used. The data 
collection instruments included various types of questions, such as opinion and value questions, ideal position and interpretive questions, feeling and sensory questions, experience and behavior questions, and open-ended questions (Merriam, 2009). These questions were carefully constructed based on the recent literature and former studies and were independently checked by many experts for adequacy, quality, relevance, completeness, and comprehensibility. The instruments also included a section on the participants' demographic information. Examples of this personal information included their name, affiliation, position, qualifications, experience, academic major, gender, and what type of learner they are.

Moreover, the process of the Delphi technique comprised the following steps: (1) developing and testing the research questions; (2) selecting ICT experts; (3) collecting data for round one; (4) summarizing responses and distributing the summary notes for round one; (5) collecting data for round two; (6) summarizing responses and distributing the summary notes for round two; (7) continuing the process until a reasonable consensus emerges; and (8) validating, generalizing, and documenting the study's findings (Anantatmula, 2007; Hsu \& Sandford, 2007). The continuous authentication throughout the Delphi method is crucial to enhance the results' reliability; thus, this should be factored in the research design (Keeney et al., 2011; Skulmoski et al., 2007). However, several scholars believe that the Delphi iteration attributes can potentially allow investigators to shape the participants' sentiments (Hsu \& Sandford, 2007).

\subsection{Sample}

According to the recommendations that were found in the Delphi literature, a stratified random sample of 80 ICT experts participated in this longitudinal qualitative study. The Delphi-qualified participants were divided into four distinguished panels, namely, academics, practitioners, government officials, and officials of non-governmental organizations. Each panel comprised 20 experts. This structure is appropriate for getting different perspectives, which can help to obtain a reasonable degree of emerging patterns or consensus regarding the topic under investigation (Okoli \& Pawlowski, 2004; Skulmoski et al., 2007).

\subsection{Data Collection}

The data were collected over a one-and-a-half-year period. The Delphi technique was comprised of the following steps: (1) assessing the research questions; (2) selecting ICT experts; (3) collecting data in round one; (4) summarizing the responses and distributing the summary notes of round one; (5) collecting data in round two; (6) summarizing the responses and distributing the summary notes of round two; (7) collecting data in round three; (8) summarizing the responses and distributing the summary notes of round three; (9) collecting data in round four; and (10) summarizing the responses and distributing the summary notes of round four (Anantatmula, 2007; Hsu \& Sandford, 2007; Skulmoski et al., 2007).

The first step was to assess the research questions. This study's research questions were independently checked by many experts in the field for adequacy, quality, relevance, completeness, comprehensibility, reliability, and validity. The completion of this step took almost two months. The second step was to select the ICT experts. The procedure for selecting the ICT experts required three months. This selection involved the following steps: (1) identifying the different panels; (2) populating the prospective names on each panel; (3) nominating the qualified experts; (4) ranking the experts; and (5) inviting the selected experts (Okoli \& Pawlowski, 2004).

The third step involved the data collection in round one. The first edition of the survey questionnaire was distributed to the Delphi participants. Each member responded to the questions that were listed on the survey. This step took six weeks for completion. The fourth step was to summarize the responses and distribute the summary notes of round one. The collected data in this phase were carefully analyzed and interpreted. This step also lasted six weeks.

The fifth step was the data collection in round two. The second version of the survey questionnaire-which was created based on round one's responses - was disseminated to the ICT experts. Each participant responded to the questions in the questionnaire. This step required six weeks to be accomplished. The sixth step was to summarize the responses and distribute the summary notes of round two. The collected data in this phase were carefully analyzed and interpreted. This step also took six weeks for completion.

The seventh step involved the data collection in round three. The third edition of the survey questionnaire - which was constructed based on round two's responses-was dispersed to the Delphi participants. Each member responded to the questions in the survey. This step took six weeks to be finished. The eighth step was to summarize the responses and distribute the summary notes of round three. The collected data in this phase were also carefully analyzed and interpreted. This step similarly lasted six weeks.

The ninth step involved the data collection in round four. The fourth version of the survey questionnaire - which 
was formed based on round three's responses - was circulated to the ICT experts. Each participant responded to the questions in the survey. This step required six weeks for completion. The tenth step was to summarize the responses and distribute the summary notes of round four. The collected data in this phase were again carefully analyzed and interpreted. This step also required six weeks for completion.

During the time period of the data collection process, the panelists were always encouraged to share their thoughts and judgments openly. They were also assured anonymity and that all the data that were gathered from the research's qualitative instruments would be confidential and only used for the purposes of this study's statistical analysis.

\subsection{Methods of Analysis}

The study's data were all recoded into a quantifiable format for data analysis purposes. In fact, all survey questionnaires - as well as the interviews and personal discussion transcripts, which needed to be performed occasionally-were coded for specific patterns throughout the research. Then, the researcher watched carefully for trends in the gathered data by using the following rule of thumb: if a statement was cited once, then it was an anecdote, and if a statement was stated twice, then it was a coincidence; however, if a statement was raised three or more times, then it was a trend (Saldaña, 2012).

Specifically, "Descriptive" and/or "Behavioral" coding, "In Vivo" coding, and "Topic" coding techniques were adopted. Descriptive and/or Behavioral coding involve the storage of information regarding the cases that are being studied - such as the attributes, characteristics, variables, or behaviors that describe each case. This organization can commonly be accomplished by importing the data into tables_-instead of selecting and coding the text — or by working in a table of cases and attributes, characteristics, variables, or behaviors. As a researcher, you attempt to allocate to each case the proper value (i.e., assign a numeric identifier) of each attribute, characteristic, variable, or behavior. Every qualitative research study uses this type of coding, which helps to broaden analysis and interpretation. In contrast, In Vivo coding involves labeling the data, such as an interview transcript, in the participant's own language using a word or short phrase for each section of the data. In Vivo coding is appropriate and relevant because of its capability to understand what is essential to the participants, and it ensures that the ideas remain as close as possible to the participants' own words. Topic coding encompasses labeling the data according to the subjects, categories, or concepts that the data are related to. All the information regarding these topics, categories, or concepts must be envisioned in the data to enable in-depth analysis and interpretation (Saldaña, 2012).

Thus, the entire purpose behind the qualitative coding process was to make more sense out of the gathered raw data, which results in more detailed and specific outcomes that can help to comprehensively and truthfully clarify the topic under investigation. Additionally, utilizing qualitative coding techniques allows the transformation of the qualitative data to a quantitative format so that the data can then be subjected to a statistical analysis. This statistical analysis includes inferential statistics such as a t-test, one-way analysis of variance (ANOVA), multiple regression correlation (MRC), and additional analyses, such as lag sequential analysis-a statistical test that recognizes sequences of behavior (Guest, MacQueen, \& Namey, 2012; Madrigal \& McClain, 2012). The collected data were then analyzed - using several methods of analysis - presented, and interpreted on the basis of the formulated objectives.

\section{Results}

\subsection{Research Question No. 1 - Identification of Appropriate Nonlinear Visual Tools}

This research question addresses the identification of a prioritized list of the most appropriate Web 2.0/3.0 tools that embrace nonlinear visual thinking, teaching, learning, and leading. The findings that were carefully derived from the collected data showed that a significant consensus emerged regarding a ranking of these tools. As indicated in their responses, approximately 97 percent of the ICT experts $(M=4.963$, and $S D=0.191)$ agreed on the following ranked list of online Web 2.0/3.0 tools: (1) Prezi, a deep-zooming storytelling presentation tool; (2) PowToon, an explainer video animation storytelling presentation application; (3) GoAnimate, video animation storytelling presentation software; (4) Sparkol VideoScribe, a whiteboard video scribing animation storytelling presentation program; (5) RawShorts, an explainer video animation storytelling presentation app; (6) emaze, an HTML5 storytelling presentation tool that creates amazing 2D slideshows, video and 3D presentations; (7) iMindMap, an interactive mind mapping storytelling presentation application; (8) Mindmeister, interactive mind mapping storytelling presentation software; (9) Adobe Voice, an explainer video animation storytelling presentation program; (10) Pixton, a comic strip storytelling presentation app; (11) Bitstrips, a social comics storytelling presentation application; (12) Kahoot!, a game-based classroom engagement tool based on response system technology that is ideal for creating online quizzes, surveys, and polls; (13) Screencast-O-Matic, a 
screencasting storytelling presentation software program; (14) Infogram, an interactive data visualization storytelling presentation program that is ideal for creating infographics; (15) Glogster EDU, an interactive poster/board storytelling presentation application; (16) iPresent, an interactive dynamic storytelling presentation tool; (17) Haiku Deck, a panoramic scrolling slideshow storytelling presentation app; (18) Storify, social media curator storytelling presentation software; (19) Tiki-Toki, an interactive timeline storytelling presentation program; (20) Make Beliefs Comix, a comic strips storytelling presentation tool; (21) dipity, an interactive timeline storytelling presentation application; (22) PeoplePlotr, an interactive plot storytelling presentation tool that is ideal for creating people plots, family trees, and company hierarchies; (23) projeqt, a panoramic scrolling slideshow storytelling presentation program; (24) Inspiration Maps, Kispiration Maps, Webspiration Classroom, or WebspirationPRO, interactive mind mapping storytelling presentation software; (25) Popplet, an interactive mind mapping storytelling presentation app; and (26) Scrollshow, a panoramic scrolling slideshow storytelling presentation tool.

\subsection{Research Question No. 2 - Criteria for Measuring the Success of Nonlinear Visual Tools}

This research question focuses on establishing the criteria for measuring the educational success of Web 2.0/3.0 tools that support nonlinear visual thinking, teaching, learning, and leading. The results that were cautiously extracted from the gathered data revealed that a significant consensus emerged regarding this criteria. In fact, the vast majority of the Delphi experts (i.e., approximately 98 percent, $M=4.975$, and $S D=0.157$ ) -as communicated in their responses - agreed on the items that were listed in the following criteria: (1) familiarity; (2) usage; (3) marketability (i.e., cost); (4) learnability; (5) usability (i.e., equitable use, intuitive use, and ease of use); (6) coherence (i.e., meaning and information must be evident and transparent); (7) nonlinearity (i.e., the flow of the information presented); (8) understanding (i.e., comprehension of the information presented); (9) malleability/flexibility (i.e., shaping the environment to suit the user's needs and tastes - to accommodate a wide range of individual preferences); (10) accessibility; (11) reliability (i.e., consistency); (12) perceptibility (i.e., the information was conveyed efficiently and effectively to the user regardless of the environment's conditions or the user's sensory abilities); (13) visual design (i.e., templates, themes, and layouts); (14) animation (i.e., zooming, movement/motion, and transitions); (15) multimedia (i.e., audio, video, text, and hyperlink capabilities); (16) memorability; (17) interactivity (i.e., interaction, collaboration, communication, and sharing); (18) attention; (19) motivation; (20) engagement (i.e., drawing the user in to practice); (21) inclusiveness (i.e., inviting and creating a sense of feeling part of a community); (22) compatibility (i.e., compliancy); (23) ownership (i.e., sense of ownership); (24) support/feedback (i.e., instructional and technical); (25) ergonomics/human factors; (26) relevancy (i.e., importance, significance, and transcendence); (27) robustness; (28) usefulness (i.e., efficiency, effectiveness, and ROI); (29) complexity; (30) comfortability (i.e., satisfaction); and (31) acceptance (i.e., overall reflection/reaction). When these attributes/factors are combined by using the right tool, they can assist a presenter in creating a meaningful and memorable experience for an audience.

The previously mentioned measurements were built around and determined by numerous attributes of the principles of the following theories: (1) Human-Centered Design (HCD) theory, guidelines of international standard ISO 13407; (2) User-Centered Design (UCD) theory; (3) Information Interaction Design (IID) theory, which according to Shedroff (1994), IID is simply the combination of Information Design (ID), Interaction Design (ID), and Sensorial Design (SD), but this term may also be denoted in other fields as Information Architecture (IA) or Instructional Design (ID); and (4) Graphic/Visual Design (G/VD) theory (White, 2011). Applying the principles of the HCD, UCD, IID, and G/VD theories will help to ascertain whether any nonlinear visual Web 2.0/3.0 application is considered to be an appropriate ICT tool for advancing excellence in thinking, teaching, learning, and education leadership in the digital knowledge age. Accordingly, this application can offer better clarification and understanding regarding these tools' effectiveness and success in education. This application will assist scholars, academics, educators, teachers, administrators, instructional technology leaders, professionals, practitioners, and policy and decision makers in determining and defining the appropriate solutions to educational challenges.

\subsection{Research Question No. 3 - Applications of the Criteria on Other ICT Tools}

This research question addresses whether the criteria for measuring the educational success of Web 2.0/3.0 tools that embrace nonlinear visual thinking, teaching, learning, and leading are different from other educational application software. The findings that were carefully extracted from the collected data demonstrated that the Delphi participants always showed some conformity regarding this issue. Approximately 99 percent $(M=4.988$, and $S D=0.112$ ) of the participants always agreed-according to their responses - that the defined criteria for measuring the educational success of Web 2.0/3.0 nonlinear visual ICT tools/services has vital educational promise and would preferably be adopted to assess and measure other educational apps. 


\section{Discussion}

The results of this longitudinal qualitative Delphi research study were very promising. The Delphi ICT experts were able to seek and reach without a doubt an overwhelmingly significant consensus on the issues that were carefully deliberated in this study. The Delphi participants were capable of determining and prioritizing a list of the most relevant, reliable, accurate, and appropriate Web 2.0/3.0 nonlinear visual tools - which are considered a priority for educators (Yanchus, 2013) - that can enhance the educational processes of thinking, teaching, learning, and leading in the digital knowledge age. Additionally, the subjects were able to recognize and prioritize certain criteria (i.e., measurements, standards, factors, benchmarks, and principles) that can assess and measure the success of Web 2.0/3.0 nonlinear visual tools and any ICT platform from educational perspectives. In addition, inferential statistics (e.g., ANOVAs and t-tests) were conducted on the collected data among the study's questions and other relevant demographic independent variables (e.g., type of ICT panelist, academic qualifications, years of experience, position, gender, and type of learner) with the objective of measuring and evaluating the Delphi participants' responses as groups. The objective of these tests was to determine whether there were any demographic differences among the research groups. The outcomes of these comparison tests divulged no significant differences among the subgroups.

The qualitative nature of the Delphi technique research design, the deployment period, and the capability to examine a large sample size of ICT experts all notably factored in strengthening the statistical significance, reliability, and confidence in the collected data. The findings of this research study are coherent and comply with the proposed assumptions.

\section{Conclusion and Recommendations}

The emergence of Web 2.0/3.0 cloud-based apps and services in the past decade has changed everything in the visual aid world. Many Web 2.0/3.0 nonlinear visual tools are available on the market. However, only several of these tools stand out from the others as real ICT competitors - if used carefully and appropriately-that have important promise for the educational processes of thinking, teaching, learning, and leading in the digital knowledge age. Academics, learners, administrators, and other practitioners who represent various educational settings worldwide - from PK-12 and higher education to professional, scientific, and research institutions - are all enthusiastic concerning the possibilities of the new applications, which can benefit their thinking styles, instructional pedagogies, learning strategies, and leadership practices (Diamond, 2010; Virtanen et al., 2013). These tools have distinctive nonlinear styles to present ideas and concepts through their user-friendly intuitive interfaces and their built-in visual, motion, communicative, collaborative, sharing, and interactive functions. However, assessing and measuring - from the educational or instructional technology perspectives - the success and impacts of these new types of ICT tools/services in all aspects of the educational arena is sensitive, time-consuming, and requires knowledgeable ICT professional personnel. Therefore, I highly recommend the following.

1. The new types of Web 2.0/3.0 nonlinear visual tools that were identified, prioritized, and revealed by this study's ICT experts should be used.

2. The criteria identified in this study form a comprehensive inventory of standards that were carefully established by this study's professional participants and were based on their experiences as well as proven research theories in the field. These criteria should be used to assess and measure the educational success and impacts of ICT apps and services.

3. Distinguished visual presenters and designers should utilize one of the visual thinking techniques that is highly recommended by Tony Buzan — an English author and educational and business consultant who is best known for his creation of mind maps: the "Incubation Period". This technique simply means that an individual must let his/her mind rest and then return to the thing he/she was doing or working on with fresh eyes (i.e., mind's eyes). Researchers have indicated that this technique enriches the "what's-missing" factor and also inspires new ideas. A person can frequently acquire a great boost of inspiration by leaving the ideas and returning to them when his/her mind is rested (Diamond, 2010). Although this method is practiced by most notable visual presenters and designers globally, its uses can go beyond visual presentations and designs and can cover all aspects of life.

4. For more inspiration on the visuals that can be used, visit the Visual-Literacy.org Website. Observe the "Periodic Table of Visualization Methods" that was created by Ralph Lengler and Martin Eppler in 2007. This is a chart of visual elements that is divided into six groups using color coding. These six groups are data visualization, information visualization, concept visualization, strategy visualization, metaphor visualization, and compound visualization. The online version of this table is interactive, and 
when you move your cursor over one of the elements on the chart, a picture pops up and displays for you what the element looks like (Eppler, 2015; Lengler \& Eppler, 2007).

5. Before you begin to brainstorm and produce ideas for your forthcoming nonlinear visual presentation or design, you should discover your thinking style. According to David W. Galenson, people possess two types of thinking styles: (a) people who approach things conceptually and have a tendency to accomplish their work swiftly with a flair for drama because they have knowledge of what exactly they crave to do and simply follow it through; and (b) people who are more experimental and are likely to perform their work carefully and quietly because they actually learn from experience and continuously make changes. Incidentally, both types of thinking styles are equally influential. However, recognizing your style enables you to comprehend how best to address brainstorming ideas for your presentations and designs (Galenson, 2007).

6. Once you consider combining ideas that you have discovered from other projects, do not hesitate to follow your ambition because this rational mode of thinking is what presently known as a "mash up". Simply stated, mash ups are products that blend technology and data from two or more other products to create a third new product (Diamond, 2010).

7. The presenter or designer's main role for a well perceived linear or nonlinear visual presentation and the supporting role of the ICT apps must be carefully emphasized because numerous issues that address ICT software seem to lie with the presenter or designer, not the tools. In fact, the presenter or designer may appear to lack the skills, competencies, and knowledge of the following: (1) data visualization; (2) information design; (3) graphic design; (4) visual design; (5) interaction design; (6) sensorial design; (7) human-centered design; (8) user-centered design; (9) learner-centered design; (10) learner-centered interaction; (11) information architecture; (12) instructional design; (13) nonlinear thinking; (14) visual thinking; (15) visual teaching; (16) visual learning; and (17) visual leadership. There is a significant desire for creativity and innovation in presentations and designs and a great need for better, well-prepared, well-skilled, and highly qualified people who are both linear and nonlinear visual presenters or designers (Thielsch \& Perabo, 2012). To read more concerning these topics, I recommend reviewing Dr. Edward R. Tufte's studies. The following are some of his noted contributions to the field: (1) "The Visual Display of Quantitative Information"; (2) "Envisioning Information"; (3) "Visual Explanations: Images and Quantities, Evidence and Narrative"; (4) "Beautiful Evidence"; (5) "Visual and Statistical Thinking: Displays of Evidence for Making Decisions"; and (6) "The Cognitive Style of PowerPoint: Pitching Out Corrupts Within".

8. As you build your visuals, you can move along numerous dimensions. However, to effectively and efficiently evaluate your design, you can utilize the evaluation method of Kurt Hanks and Larry Belliston. Their projected procedure allows you to assess your design by using the following scales: whole to parts, known to unknown, simple to complex, coarse to refined, rough to finished, vague to clear, and small to large. You can thoroughly consider your design and then determine how you can utilize the ICT software's built-in features to display elements that are along both extremes of the continuum. Make certain that you move along both ends of the continuum so that your visuals are multidimensional (Hanks \& Belliston, 2006).

9. Because storyboarding - visually organizing material-is critical for linear and nonlinear visual storytelling presentations/designs, I recommend carefully planning out the full view of the visual presentation (i.e., the metaphor design/layout). The presentation can retain and control the learners' attention if the visual is carefully constructed. I also suggest having a thoughtful navigational plan that rationally and carefully emphasizes the movements, zooms, and rotations. I also recommend sensibly determining the general path of the visual presentation/design. Some examples may include horizontal navigation, vertical navigation, and clock-wise navigation (Houska, 2013).

10. The new ICT tools and services are best learned through the completion of authentic (i.e., real life) motivational tasks, activities, assignments, and projects, as well as scaffolded, self-directed, learner-centered, integrated, just-in-time, and connected thinking, teaching, and learning strategies. These are all valid (i.e., research-proven) and useful techniques (Perkins, 2009).

11. More research studies should be conducted using the Delphi technique with larger sample sizes that cover a wide range of ICT trends and issues that are important to revolutionize the educational processes of thinking, teaching, learning, and leading in the digital knowledge age. 


\section{References}

Anantatmula, V. (2007). Knowledge management's impact on organizational performance. In M. E. Jennex (Ed.), Knowledge management in modern organizations (pp. 121-141). Hershey, PA: Idea Group Publishing. http://dx.doi.org/10.4018/978-1-59904-261-9.ch008

Arden, J. (2014). The brain bible: How to stay vital, productive, and happy for a lifetime. Columbus, OH: McGraw-Hill Education.

Arden, J. B. (2010). Rewire your brain: Think your way to a better life. Hoboken, NJ: Wiley/Jossey-Bass Education.

Diamond, S. (2010). Prezi for dummies. Hoboken, NJ: Wiley/Jossey-Bass Education.

Eppler, M. J. (2015). Visual-literacy.org: An e-learning tutorial on visualization for communication, engineering, and business. Retrieved from http://www.visual-literacy.org/index.html

Galenson, D. W. (2007). Old masters and young geniuses: The two life cycles of artistic creativity. Princeton, NJ: Princeton University Press.

Girvan, A. (2010). Never sit through a PowerPoint again: The power of Prezi. Retrieved from $\mathrm{http} / / /$ andrewgirvan.com/never-sit-through-another-powerpoint-the-power-of-prezi/

Guest, G., MacQueen, K. M., \& Namey, E. E. (2012). Applied thematic analysis. Thousand Oaks, CA: SAGE Publications. http://dx.doi.org/10.4135/9781483384436

Hanks, K., \& Belliston, L. (2006). Rapid viz: A new method for the rapid visualization of ideas (3rd ed.). Independence, KY: Cengage Learning.

Hill, A., Arford, T., Lubitow, A., \& Smollin, L. M. (2012). "I'm ambivalent about it": The dilemmas of PowerPoint. Teaching Sociology, 40(3), 242-256. http://dx.doi.org/10.1177/0092055X12444071

Houska, J. A. (2013). Pedagogically sound use of Prezi: Making effective use of Prezi in the classroom. Retrieved from http://www.apa.org/ed/precollege/ptn/2013/05/prezi-sound.aspx

Hsu, C.-C., \& Sandford, B. A. (2007). The Delphi technique: Making sense of consensus. Practical Assessment, Research \& Evaluation, 12(10). Retrieved from http://pareonline.net/pdf/v12n10.pdf

Jacobson, J. P. (2012-13, December/January). Skip the essay: Have students make Prezicasts. Learning \& Leading with Technology, 40(4), 34-36.

Jensen, J., \& Tunon, J. (2012). Free and easy to use Web based presentation and classroom tools. Journal of Library \& Information Services in Distance Learning, 6(3-4), 323-334. http://dx.doi.org/10.1080/1533290X. 2012.705157

Keeney, S., Hasson, F., \& McKenna, H. (2011). The Delphi technique in nursing and health research. Hoboken, NJ: Wiley/Blackwell. http://dx.doi.org/10.1002/9781444392029

Lengler, R., \& Eppler, M. J. (2007). Towards a periodic table of visualization methods for management. Retrieved from http://www.visual-literacy.org/periodic_table/periodic_table.pdf

Madrigal, D., \& McClain, B. (2012). Strengths and weaknesses of quantitative and qualitative research. Retrieved from http://www.uxmatters.com/mt/archives/2012/09/strengths-and-weaknesses-of-quantitative-a nd-qualitative-research.php

Medina, J. (2014). Brain rules: 12 principles for surviving and thriving at work, home, and school (2nd ed.). Seattle, WA: Pear Press.

Merriam, S. B. (2009). Qualitative research: A guide to design and implementation (2nd ed.). San Francisco, CA: Jossey-Bass.

Okoli, C., \& Pawlowski, S. D. (2004). The Delphi method as a research tool: An example, design considerations and applications. Information \& Management, 42(1), 15-29. http://dx.doi.org/10.1016/j.im.2003.11.002

Panag, S. (2010, August). A Web 2.0 toolkit for educators. Youth Media Reporter, 4(4), 89-91.

Perkins, J. (2009). Where are the instructions? Understand more, remember better: Learning to use Prezi in the $21^{s t}$ century. Retrieved from http://jperk30.edublogs.org/files/2009/10/MDN642_Sem2_09-Poster-assign ment-Joseph-Perkins-n4993535.pdf

Perron, B. E., \& Stearns, A. G. (2011). A review of a presentation technology: Prezi. Research on Social Work Practice, 21(3), 376-377. http://dx.doi.org/10.1177/1049731510390700 
Rockinson-Szapkiw, A. J., Knight, A., \& Tucker, J. M. (2011). Prezi: Trading linear presentations for conceptual learning experiences in counselor education. Retrieved from http://works.bepress.com/amanda_rockinson_ szapkiw/18/

Saldaña, J. (2012). The coding manual for qualitative researchers (2nd ed.). Thousand Oaks, CA: SAGE Publications.

Schiller, K. (2011). High-tech classrooms. Information Today, 28(8), 34-35.

Shedroff, N. (1994). Information interaction design: A unified field theory of design. Retrieved from http://www.nathan.com/thoughts/unified/

Sheffield Marketing Partners. (2013, May 11). TREND: The need for condensed, visual presentations mark the slow demise of PowerPoint. Marketing Weekly News, p. 185.

Simon, A. (2011). Why Prezi is a better educational tool than PowerPoint. Retrieved from http://adamsimon.org/ why-prezi-is-a-better-educational-tool-than-powerpoint/

Skulmoski, G. J., Hartman, F. T., \& Krahn, J. (2007). The Delphi method for graduate research. Journal of Information Technology Education, 6(1), 1-21. Retrieved from http://www.jite.org/documents/Vol6/JITE v6p001-021Skulmoski212.pdf

Thielsch, M. T., \& Perabo, I. (2012). Use and evaluation of presentation software. Technical Communication, 59(2), 112-123.

United Nations Educational, Scientific and Cultural Organization. (2005). Education for all: Ensuring universal access to education and to information and communication technologies. Paris, France: United Nations Educational, Scientific and Cultural Organization.

United Nations Educational, Scientific and Cultural Organization. (2013). UNESCO global report: Opening new avenues for empowerment - ICTs to access information and knowledge for persons with disabilities. Paris, France: United Nations Educational, Scientific and Cultural Organization.

Virtanen, P., Myllärniemi, J., \& Wallander, H. (2013). Diversifying higher education: Facilitating different ways of learning. Campus-Wide Information Systems, 30(3), 201-211. http://dx.doi.org/10.1108/10650741311 330384

Watrall, E. (2009). Challenging the presentation paradigm: Prezi. Retrieved from http://chronicle.com/blogs/ profhacker/challenging-the-presentation-paradigm-prezi/22646

White, N. L. (2011). Prezi v. PowerPoint: Finding the right tool for the job. Retrieved from https://docushare.sunyit.edu/dsweb/Get/Document-196824/White_ThesisProject2.pdf

Yanchus, K. (2013). School libraries evolving into $21^{\text {st }}$ century learning spaces. Retrieved from http://www. flamboroughreview.com/news/school-libraries-evolving-into-21st-century-learning-spaces/?utm_source=rss \&utm_medium=rss\&utm_campaign=school-libraries-evolving-into-21st-century-learning-spaces

Zhang, W. (2012). Technology in college classrooms: An action research examining the use of PowerPoint in ELL classrooms (Doctoral dissertation). Available from ProQuest Dissertations \& Theses: Full Text (3528633).

\section{Copyrights}

Copyright for this article is retained by the author(s), with first publication rights granted to the journal.

This is an open-access article distributed under the terms and conditions of the Creative Commons Attribution license (http://creativecommons.org/licenses/by/3.0/). 